\title{
On the role of the concept of noospheric knowledge in the era of technoscience
}

\author{
Irina Chernikova ${ }^{1 *}$, Daria Chernikova $^{2}$, and Mariya Yazevich $^{3}$ \\ ${ }^{1}$ Tomsk State University, Faculty of Philosophy, 634050 Tomsk, 36 Lenin Ave., Russian Federation \\ ${ }^{2}$ Tomsk State University, Faculty of Philosophy, 634050 Tomsk, 36 Lenin Ave., Russian Federation \\ ${ }^{3}$ T.F. Gorbachev Kuzbass State Technical University, Department of History, Philosophy and Social \\ Sciences, 650000 Kemerovo, 28 Vesennya st., Russian Federation
}

\begin{abstract}
The article examines the changes that characterize modern science and scientific research, which have been embodied in the phenomenon of technoscience. Technological science is distinguished from traditional science by a new form of cognitive organization, integrating fundamental and applied research, natural science and human knowledge. It is both a theoretical activity for the production of ideas and social practice. It is substantiated that technoscience, which is both a theoretical construct and a social practice, embodies the project of noospheric knowledge, about which the outstanding Russian scientist V.I. Vernadsky wrote. His teaching expressed the idea of a new science, and by characterizing it, he stressed that science can't be considered only as a collection of facts and limited to its instrumental functions, he understood it as the most powerful and important spiritual movement, contributing to the formation of the noosphere - the sphere of reason. Scientific knowledge, which is formed in the consequence of integrative tendencies in modern science, manifested in the systemic and holistic scientific worldview, in transdisciplinary studies, in the convergence of natural science and humanities knowledge, is designated as technoscience. It is shown that the noospheric science of V.I. Vernadsky, based on the wise mind, which he foresaw as the coming stage of the natural historical process, can be compared with the phenomenon of technoscience.
\end{abstract}

\section{Introduction}

Characterizing the changes in modern science, it should be noted the formation of a postnonclassical paradigm of scientific rationality; changing the structure of scientific knowledge, from the disciplinary organization of science to transdisciplinary research; A new way of producing knowledge is moode-2; changes in the interaction between science and society. Classical science was presented as an "ivory tower", a special world in which both the processes taking place and their results are available only to a certain category of people - scientists. Today, science is inseparable from society. As B. Latour noted, if earlier

\footnotetext{
*Corresponding author: chernic@mail.tsu.ru
} 
society surrounded autonomous science, but remained an outsider in relation to the principles and methods of functioning of scientific rationality, now science and what we, using the traditional term, call society, intervened in each other [1. P. 209].

\section{Materials and methods}

Changing the place of science in society and the way in which knowledge is gained has found expression in the emergence of such a phenomenon as "technoscience", which is now the subject of close study [2], [3]. Technoscience is seen as a modern form of scientific activity in which science and technology form a kind of hybrid of theoretical activity and social practice. "The peculiarity of technoscience is that its objects are not a subject reality in the Cartesian dualistic picture of the world, but so-called human-sized objects. The main feature of technoscience is high social and practical orientation. Technoscience is not a technical science, but a new form of science organization, integrating many aspects of both natural science and technology and humanitarian cognition" [4. P. 12].

New forms of scientific knowledge, such as technoscience, social evaluation of technology can't be assessed unequivocally as applied or fundamental research. In these areas of scientific activity, the results of scientific research are drawn up in social action projects, in the recommendations necessary for decision-making. By characterizing technoscience, researchers pay attention to the new relationship between fundamental and applied scientific knowledge. The rigid separation of fundamental and applied research is removed, as a result of human innovation the reality itself is transformed, as the boundary between natural and artificial is blurred.

The most important aspects, in our opinion, were one of the first to single out V.S. Shvyrev in the characterization of technoscience. He correlated technoscience with the postnonclassical paradigm of scientific rationality, because in both cases cognition is not a simulation of the "natural" reality that exists outside of man. The picture of the world with which technoscience deals is not an object, but touches the human world. It goes beyond narrow technology (building engineering and technical structures), because it causes a change in the associated design and constructive consciousness. Unlike classical and nonclassical, "post-classical rationality is not purely cognitive rationality, pretending to model reality "as it is", it acts as a form of socio-humanitarian design and constructive rationality" [5. P. 45].

One of the authors of the article shows that NBIC-technologies are an example of technoscience [6]. Special NBIC-based social development programs have been adopted in America and Europe. NBIC- technologies are not just another scientific and technical improvement, they are today the main factor of social dynamics, affecting the development of civilization as a whole and each person individually. However, it is not clear whether and how the appropriate system of ethics and prohibitions will be enshrined as regulators of the new stage of civilizational development.

One of the most important characteristics of post-non-classical science is the extremely rapid introduction of the results of scientific and technological progress in our lives. The main value is innovation, yesterday's laboratory research today can be a new technological achievement accessible to humans. If fundamental installation of classical science was fundamentalism and universalism, then for postnonclassical such are innovations. In practice, this is manifested as the absence of a time interval between the development and implementation of scientific results. The norms of scientific activity become dynamic, they are "formed in the horizon of interaction of the scientific picture of the world and the life world, clearly demonstrating dependence on the goals set by the scientific community and on the accepted internal norms" [7. P. 48]. 
In technology, knowledge is made not only in the context of discovery and fundamental justification, but also in the context of the assessed consequences of their application. In the transdisciplinary studies of postnonclassical science, the axiological aspect of the philosophical foundations of technoscience is of particular importance. Risks of technological science, socio-environmental consequences of technological disasters, the need to introduce social and humanitarian examination as a special type of activity, have led to the formation of such a new scientific discipline and social practice as a social assessment of technology, which is a form of ethics of postnonclassical science.

\section{Results and discussion}

In the post-industrial society, the conditions for learning have changed, and, as noted above, the target attitudes of scientific activity have been transformed. Interaction within the scientific community, as well as between teams, takes a disintegrating or integrating character depending on the circumstances. Scientific communities can be formed to address a particular problem and function not on a permanent basis, but rather a limited time period to achieve the goal, such as invisible colleges as a form of non-institutionalized scientific activity. All this has an impact on the existing scientific ethos, which takes a more complex character in such conditions. Researchers note that the formation of modern society, a new style of economy based on the achievements of the Fourth Technological Revolution, is directly related to the change in the values paradigms, ethical principles of science, and, ultimately, the subject itself [8]. Thus, profound changes in the field of science attract radical changes in the scientific ethos, formed ethos of technoscience.

Unlike the Merton ethos of science regulating scientific activity within the scientific community, the ethos of post-classical science is more complex and heterogeneous. The complexity of the technological ethos is determined primarily by the fact that here we are dealing with a transdisciplinary organization of scientific knowledge, with converged technologies combining bio- nano, cognitive, information technologies. The inner and outer contours of science are highlighted. According to B.G. Yudin, the inner circuit is based on the diverse connections between science and technology. External contours are complemented by such connections as business, financing the development of new technologies, human relations as a consumer of scientific developments, a society in which all the relationships between the blocks of this circuit are carried out [9].

Is the ethics of technoscience an applied ethic that exists in addition to the internal ethics of science in the form of the ethical content of various components of NBIC technologies: nanoetics, bioethics, information ethics, neuroethics? Or is the ethics of technoscience a holistic meaning-forming system in which applied, theoretical and sociohumanitarian, hermeneutic aspects are converged? To answer the questions raised, we should refer to the analysis and evaluation of the components of the ethics of technoscience.

Bioethics has been formed since the late sixties of the XX century. Initially, the subject of bioethics was the discussion and evaluation of new biomedical practices, but with the development of biotechnology there were many ethical, anthropological, ontological problems, in search of answers to which the subject space of bioethics was formed. The most significant change in the situation in the field of bioethics is due to the fact that at the present stage of science, man is not only a consumer of various products of technology, but also becomes a target of these influences. Human improvement programmes aimed at improving the quality of life did not raise the issue of changing human nature, but today converged technologies can transform the biological nature of man and thus undermine the basis of human identity. This path of human development is discussed by the proponents of transhumanism. Bioethics, whose mission is to help predict the possible consequences of 
the use of biomedical technologies, is not only a scientific discipline, but also a social practice aimed at preserving the person and his values.

Additional light on the problem of human nature is shed by research, called cultural neuroscience and neuroethics. Neuroethics is interpreted not only as an applied ethic that defines the boundaries of medical intervention in the study of the brain, but also as a complication of philosophical ethics, as the ontological foundation of morality itself is called into question. Modern technologies and neuroscience allow to see which parts of the brain are activated in certain actions, experiences. The development of neuroscience and 3D brain mapping technologies have contributed to the formation of neuroethics, however, the essence of morality is that it characterizes a person not as a being, but in his quest for the ideal, for the proper. Human actions are not always explained as causal or utilitarian conditioned. The philosophical context of neuroethics is associated with the need to morally assess the effects of cognitive technology and neuroscience on humans.

Information ethics is an area of ethics aimed at studying the moral and ethical problems of the development of information technology, as well as the ethical and legal aspects of the development of electronic culture in the information society. Its formation and development is connected with the spread of the Internet. Information ethics, according to professor of Oxford University, one of the leading experts in the philosophy of information technology L. Floridi, is not only a component of the philosophy of information, but a discipline that opens a new practical dimension and carries out the moral regulation of the infosphere [10]. R. Capurro distinguishes information ethics in a broad sense, covering the ethical problems of the entire information and communication sphere, including the media, and information ethics in a narrow sense, as ethical issues of digital technologies. As the most relevant for information ethics, it singles out topics such as intellectual property, privacy, security, information overload, digital divide, gender discrimination, artificial "mediators," virtual reality, robotics, reliable and up-to-date information about the environment and censorship [11].

Thus, technological science is distinguished, first, by the transdisciplinary organization of scientific knowledge - it is socially distributed knowledge; Second, a new way of producing knowledge; third, a new ethos. All this allows us to see in technoscience a special form of social practice, not just theoretical knowledge. V.I. Vernadsky is not only an outstanding scientist in the field of mineralogy and geology, but a unique thinker who developed the doctrine of the noosphere, which influenced the understanding of the role of man and science as a factor in the development of the biosphere, as well as the evolution of the cosmos. His teaching expressed the idea of a new science, characterizing which, he stressed that science "is not a logical construction, looking for the truth apparatus. It is impossible to know the scientific truth by logic, only by life" [12. P. 54]. V.I. Vernadsky considered science not only as a collection of facts and was not limited to its instrumental functions, but understood it as the most powerful and important spiritual movement, contributing to the formation of the noosphere - the sphere of reason. The noosphere is interpreted by V.I. Vernadsky as the realm of reason and, at the same time, as a new geological phenomenon on the planet, it is a biosphere transformed by scientific thought.

The idea of the noosphere is associated with the moral image of people, the moral beginning of civilization. The meaning of this symbol can be translated into our cultural context by the synthesis of the following concepts: intuition - thought - mind consciousness - wisdom - spirit. If in the picture of the world built by classical science man was not present, since the second half of the twentieth century, many scientific programs are practically important for the protection of the environment, the survival of mankind. These programs require the integration of both humanitarian and natural science professionals. The development directed by the mind has become the subject of the 
noospheric concept of V.I. Vernadsky, in his understanding of the noosphere - an area of life, governed by the mind [13].

The noospheric teachings of V.I. Vernadsky originated and developed in an intellectual environment whose name is Russian cosmism. In modern science philosophy, the appeal to cosmism is associated with the problems that arise in the situation of the global civilizational crisis - it is ecological, evolutionary, the problem of survival. The noospheric concept today is sometimes regarded as a utopian worldview, where the desired is presented as valid. In essence, proponents of such assessments of the noosphere question the existence of the "kingdom of reason" and the rationality of being a modern man, who was on the verge of death and endangered the biosphere as a whole. For the representatives of Russian cosmism, the growth of science and the power of humanity in the environment is, first of all, an evolutionary phenomenon, a natural-historical process. "Nowhere do we see," - says V.I. Vernadsky, - "any weakening of the scientific movement, despite wars, exterminations, loss of life from murders and diseases. All these losses are quickly compensated by the powerful rise of the real achievements of science and its organized state power and technology. It even seems that in this cycle of human unhappiness it (the noosphere) grows even more and includes the very means to stop trying to strengthen barbarism" [14. P. 339].

The distinctive feature of Russian cosmism, as a mindset expressing a certain ontology, is the "gluing" of everyday and moral components. Ethical themes are related to evolutionary and environmental ideas. In the mechanistic picture of the world, where matter "hastens without end and without meaning" (A. Whitehead), and the generation and existence of man has nothing to do with the world in which he lives, eventually formed an alienated, consumeristic attitude to nature. In the picture of the world, affirmed by the cosmists, on the contrary, a worldview is formed, containing not only economic, technological values, but values of the ethical plan. In modern science, the concept of the noosphere is largely seen in the context of environmental issues, particularly in relation to the sustainable development program of society [15]. The survival strategies of mankind correlate with the stages of the formation of the noosphere. They single out the stages of information, environmental and space society as phases of noospherogenesis. The formation of a single information and unified ecological space has already become a reality.

The science, the formation of which V.I. Vernadsky foresaw, can be defined by the term noospheric science, and the knowledge produced by it as noospheric knowledge. Noospheric knowledge is knowledge that contains information not only about the object and how it is transformed and used, but also about the conditions and consequences of introducing scientific technologies into the social process. Noospheric knowledge is formed in the consequence of integrative tendencies in modern science, manifested in the systemic and holistic scientific worldview, in transdisciplinary studies, in the convergence of natural science and human knowledge. The beginning of this new form of knowledge is laid by the noospheric concept of V.I. Vernadsky, in which evolution is understood as coevolution - a joint evolution of the system and its environment.

\section{Conclusion}

Modern science, in particular, the form of technoscience discussed above, refers to selfdeveloping complex systems, to "human-sized" objects. With the transition to technoscience to the system of values and norms characteristic of classical science, a system of values and norms specific to the production organization has been added, and in post-industrial society, the system of social and humanitarian values associated with the functioning of society is one of the central themes of responsibility. On the basis of the above we come to the conclusion that there is a significant modification of the ideal of self- 
value of scientific technological innovation as the basis of the value of man-made civilization. Such forms of activity as social expertise, responsible research and innovation (RRI), social evaluation of technology, deep ecology connect scientific research with different types of social practices. Science appears in a new humanistic dimension to ensure that the technologies being developed are in accordance with social values and ensure the sustainable development and survival of mankind.

Traditional science, based on "pure reason", has taken value, moral and ethical issues beyond the actual scientific research. Unlike the Merton ethos of science, which regulates scientific activity within the scientific community, the ethos of technoscience is more complex and heterogeneous. The complexity of the technological ethos is determined primarily by the fact that here we are dealing with a transdisciplinary organization of scientific knowledge, with converged technologies combining bio-nano, cognitive, information technologies. The search for truth, which characterizes scientific cognition, persists, but the requirements for the search for truth are matched with humanistic ideals and supplemented by ethical regulations. Thus, the model of the noospheric science of V.I. Vernadsky based on the wise mind, which he foresaw as the coming stage of the naturally historical process, can be compared with the phenomenon of technoscience.

\section{References}

1. B. Latour, From the world of science to that of research, Science magazine, 280, 5361 (1998)

2. V.G. Gorokhov, Technosciencea is a new stage in the development of modern science and technology, Higher education in Russia, 11 (2014)

3. A. Grunwald, Technology and Society: Western-European experience in researching the social consequences of scientific and technological development (Moscow, Logos, 2010)

4. I.V. Chernikova, Technoscience in the system of scientific knowledge, Technoscience and social evaluation of technology (philosophical and methodological analysis), (Tomsk.: Ed-vo Tomsk Un-ty, 2015)

5. V.S. Shvyrev, On the ratio of cognitive and design-constructive functions in classical and modern science, Cognition, understanding, design (Moscow IF RAS, 2008)

6. I.V. Chernikova, Relationship of Fundamental Knowledge and Technological Projects of Science, Epistemology and Philosophy of Science, 38, 4 (2013)

7. L.P. Kiyashchenko, Ethos of pos-nonclassical science (to the problem). Philosophy of science, Ethos of science at the turn of the century, 11 (Moscow, IF RAS, 2005)

8. L.V. Bayeva, Ethics and the axiology of innovative science, Information Society, 2 (2011)

9. B.G. Yudin, Technoscience and "improvement" of man, Epistemology and philosophy of science, XLVIII, 2 (2016)

10. L. Floridi, Information, A Very Short Introduction. (Oxford, 2010)

11. R. Capurro, Information Ethics. Access mode: http://emag.iis.ru/arc/infosoc/emag.nsf/BPA/7c972fbe98fca119c32577dc0036bb4f

12. V.I. Vernadsky, Philosophical thoughts of a naturalist, 520 (Moscow, Nauka 1988)

13. V.I. Vernadsky, Diary Records., Archive of the Russian Academy of Sciences, 518, 2, $(1922-1924)$

14. V.I. Vernadsky, About Science. Scientific knowledge. Scientific creativity. Scientific thought. Dubna: Ed. Phoenix Center, 1 (1997)

15. A. Bel'kov, V. Zolotukhin, N. Zolotukhina, N. Sedina, M. Kozyreva, The Solution of Environmental Problems and the Dynamics of Demographic Processes in Industrialized Regions E3S Web of Conferences 134, 03005 (2019) 